\title{
Exu-Piá, uma outra visão de Macunaíma'
}

Elizabeth Maria Mendonça Real ${ }^{2}$

1. Texto apresentado no $13^{\circ}$ Encontro da Sociedade Brasileira de Estudos de Cinema e Audiovisual - Socine, realizado de 6 a 10 de outubro de 2009.

2. Jornalista, doutoranda em Comunicação na Universidade Federal Fluminense. E-mail: real.beth@gmail.com 


\title{
Resumo
}

Em Exu-Piá, coração de Macunaíma - adaptação de Macunaíma, o herói sem nenhum caráter, de Mário de Andrade - o diretor Paulo Veríssimo dialoga com momentos cruciais da cultura brasileira: o Modernismo e o Tropicalismo. No retorno ao movimento modernista brasileiro, vemos como a busca da noção de brasilidade é retomada, em um processo antropofágico, nos anos tropicalistas e adaptada nos anos 1980 por Paulo Veríssimo, numa versão apropriada aos novos tempos.

\section{Palavras-chave}

cinema brasileiro, Macunaíma, Exu-Piá, coração de Macunaíma

\begin{abstract}
Exu-Piá, coração de Macunaíma is a film adaptation of Mario de Andrade's novel Macunaíma, o herói sem nenhum caráter. In this film, the director Paulo Veríssimo dialogues with two of the most important movements of Brazilian culture: Modernism and Tropicalism. In his reassessment, Veríssimo develops again the notion of Brazilian identity taken from the "anthropophagic" and Tropicalism movement, reinterpreting them in the 1980s context, an appropriate version to the new times.
\end{abstract}

\section{Keywords}

brazilian cinema, Macunaíma, Exu-Piá, coração de Macunaíma 
temáticas

livres

\section{A trajetória de um diretor desconhecido}

Exu-Piá, coração de Macunaíma, dirigido por Paulo Veríssimo e finalizado em 1983, é uma versão cinematográfica do livro de Mário de Andrade - Macunaíma, o herói sem nenhum caráter - nunca exibida em circuito comercial, embora tenha recebido o prêmio de "Melhor Filme em 16 mm" do $18^{\circ}$ Festival de Brasília, em 1985, e tenha sido selecionada para representar o Brasil na seção "Fórum” do Festival de Berlim, no mesmo ano.

Foi o único longa do diretor falecido em 2007, que, no entanto, realizou uma série de curtas-metragens, entre eles o episódio “Os meninos do Padre Bentinho", do longa Como vai, vai bem?, produzido em 1968 pelo grupo Câmara, um coletivo formado por jovens iniciantes ávidos por se profissionalizar no setor cinematográfico. Esse filme foi realizado com baixíssimo orçamento e financiado por um sistema de cotas vendidas pelo grupo a intelectuais e profissionais da área.

Inspirado principalmente pelos filmes italianos de episódios, o grupo Câmara pretendia se dirigir a um público popular, optando por temáticas urbanas e um tom próximo às chanchadas. Veríssimo declarava a intenção deliberada, por parte dos diretores, de realizar um "anti-Cinema Novo". Buscavam romper com a visão sofisticada que o movimento mantinha em relação à sociedade brasileira e tentavam aproximar-se do dia a dia da população sem a mediação de instrumentos intelectualizados. Como cinema, o projeto do grupo era estabelecer uma relação direta com a tradição de uma dramaturgia popular da comédia urbana baseada em tipos.

Em seguida, no início da década de 1970, Veríssimo realizou alguns curtas documentais sobre músicos como Jorge Ben (1970), Milton Nascimento (1971) 
e Baden Powell (1974). Em outros curtas da mesma década, a temática em torno do lendário afro-indígena e a ligação com escolas de samba prenunciavam a versão de Veríssimo para o livro de Mário de Andrade, a ponto de o diretor considerá-los “degraus” para o longa que realizaria mais tarde.

Em Antropofagia ou Mais forte que o Catiti Catiti são os poderes do Jabuti (1979), ele se baseou nos manifestos "Pau Brasil" (1924) e "Antropófago" (1928), buscando flagrar no carnaval de rua carioca cenas que pudessem ilustrar as principais ideias de Oswald de Andrade. Outros dois curtas baseados em lendas carajás - A cabeleira urubu-rei (1979) e A estrela Tainá-kan vista do Estácio (1979) - foram filmados no morro de São Carlos, com pessoas envolvidas na escola de samba Estácio de Sá, cujo enredo, no carnaval de 1979, seria sobre os carajás: Das trevas à luz do sol - uma odisséia Karajá.

Outro filme de Paulo Veríssimo, Bahira, o grande burlão, punha em destaque a figura de Nunes Pereira, estudioso do folclore nacional. Nesse filme, o diretor mesclava o imaginário indígena, provindo da lenda de Bahira, e o ambiente urbano carioca. O próprio Nunes Pereira é o personagem central. O espectador o acompanha desde sua casa, em Santa Teresa, até o centro da cidade. Idoso, ele utiliza uma bengala para andar pelas ruas tortuosas do bairro e pegar o bonde.

Aos poucos, o filme abandona o registro meramente documental e incorpora ficcionalmente o mito de Bahira, tema de um livro de Nunes Pereira. ${ }^{3} \mathrm{O}$ bonde onde viaja o protagonista é invadido por figuras vestidas de índio. A montagem alterna habilmente momentos (sempre em preto e branco) em que o transporte é ocupado por pessoas comuns e outros (em cor) em que um homem e algumas mulheres, caracterizados como índios, além de um provocador Curupira, cercam o pesquisador. Também em cor são as inserções de planos de animais da mata brasileira: araras, corujas, jacarés, alguns presos em jaulas. 
ano I número |

temáticas

livres

O bonde, coberto com folhas de bananeira e enfeites indígenas, é contraposto ao moderno metrô, onde pessoas sisudas, provavelmente a caminho do trabalho, leem o jornal. Durante o percurso do bonde povoado de indígenas, dois garotos penduram-se nos estribos, pegando carona, como faziam usualmente em Santa Teresa. Os meninos, que pertencem à esfera do cotidiano e não à do extraordinário, incorporam o espírito lúdico proposto pela instância imaginária do filme.

Libertário, o filme tem uma acentuada tonalidade erótica. Em voz over, o discurso de Nunes Pereira ressalta a sabedoria e a harmonia do modo de viver indígena. No ano da lei da Anistia (1979), o velho pesquisador celebra a liberdade:

\footnotetext{
A selva nos dá lições extraordinárias de consciência da personalidade, sobretudo do destino que nos cabe a nós como seres humanos. Nada nos dá um sentido de liberdade como os horizontes dos campos. Eu ganhei através da selva amazônica, através dos campos, um sentido de liberdade que nós não temos. (Trecho retirado do filme.)
}

Outro curta de Veríssimo, A visão do gavião tupinambá, tinha como tema a história de Aimberê, um dos principais guerreiros tupinambás durante a revolta indígena contra os colonizadores portugueses, que tinha sido também inspiração para o enredo da escola de samba Caprichosos de Pilares (No mundo do Tupinambá). Segundo Veríssimo, nesse filme, o índio desce de um disco voador, voltando à Terra 400 anos mais tarde. Essa ideia será repetida pelo diretor em Exu-Piá, já que seu Macunaíma retorna do espaço, onde vivia transformado em estrela.

\section{Exu-Piá, coração de Macunaíma}

Como vemos, Exu-Piá é coerente com toda a trajetória de Paulo Veríssimo. O interesse pela música brasileira, tema dos primeiros curtas, está estampado no 
longa, não apenas na trilha sonora diversificada (que alterna cantos indígenas e tambores africanos, além do samba, do pop, do rock, da música circense, da bossa nova e da música erudita), mas na própria apresentação dos músicos Marku Ribas e Hermeto Pascoal. No filme Como vai, vai bem? flagramos a opção por temas populares e pelo tom bem-humorado, predominantes em Exu-Piá. E, nos filmes de temáticas indígenas - nos quais as fronteiras entre documentário e ficção, ou entre instâncias que representam o cotidiano e o imaginário, tornam-se cada vez mais tênues -, vários elementos se relacionam com o longa, incluindo o próprio diálogo com uma escola de samba.

O filme parte de um suposto retorno do personagem Macunaíma diretamente do espaço, para onde partira, transformado em estrela, no final do livro de Mário de Andrade. Extremamente fragmentado, Exu-Piá constitui-se como uma heterogeneidade de elementos derivados de fontes diversas, como um quadro partido de situações que desafia a compreensão do espectador. Veríssimo o compara a um jogo de armar, um "bricabraque", segundo sua própria definição.

Valendo-se de uma montagem fragmentária e ágil, o diretor sobrepõe elementos da cultura de massa e da cultura popular. Evoca personagens clássicos de Hollywood, por exemplo, exibindo Grande Otelo travestido de ET em imagens feitas em vídeo, oriundas de um comercial para TV protagonizado pelo ator. Estampa na tela, como recurso narrativo, o cartaz luminoso e o outdoor que remetem ao mundo urbano e à publicidade, numa clara referência a $O$ bandido da luz vermelha, de Rogério Sganzerla. Ao mesmo tempo em que mostra cartuns americanos na TV, dá destaque a dois locutores sertanejos no rádio. Há também inserções muito rápidas de planos mostrando danças dramáticas folclóricas, filmadas no Pará, provável referência ao Mário de Andrade folclorista, autor do livro Danças dramáticas do Brasil.

Macunaíma é interpretado por dois atores: Grande Otelo (ator que interpreta o personagem também no filme de Joaquim Pedro de Andrade, de 1969) e 
ano I número I

temáticas

livres
Carlos Augusto Carvalho (ator que interpreta Macunaíma na peça de Antunes Filho, em 1978), uma duplicidade procurada pelo diretor, representando, segundo ele, o negro e o caboclo, o cinema e o teatro, o velho e o novo. Não existe um único centro que conduz a narrativa. A história é contada por várias vozes: por um homem (o próprio Veríssimo), por uma mulher, por uma dupla de radialistas sertanejos.

Muitas sequências são filmadas nas ruas ou na favela, incorporando a reação do povo, por exemplo, quando Grande Otelo anda pela avenida, espantado com o progresso, ou quando, no final do filme, os personagens caminham pelas ruelas da favela (com Grande Otelo travestido como uma respeitável anciã) e são rodeados pelas crianças que se divertem com os atores. Veríssimo flagra também a tristeza popular no velório do ex-jogador Garrincha.

Há uma espécie de clipe dentro do filme, na praia, quando, passeando de carro, Macunaíma/Grande Otelo se mostra fascinado com as mulheres cariocas que sorriem e se exibem para a câmera. A sensualidade feminina é fortemente marcada no filme, seja na figura de Iriqui, em Vei, a Sol, e suas filhas, ou nos planos de mulheres seminuas vistas de longe pela janela, como partindo de um olhar voyeurístico - uma flagrante correspondência com o erotismo que permeava o cinema brasileiro na década de 1980.

De acordo com declarações de Paulo Veríssimo, os processos de criação e produção de Exu-Piá foram extremamente anárquicos, subvertendo a ordem da realização cinematográfica. Efetuaram-se, simultaneamente, filmagem e montagem, sem a direção de um roteiro fechado e com a incorporação de fatos externos ao filme, como o velório de Garrincha, em um processo de trabalho em que se fundem inextricavelmente arte e vida. "Pela primeira vez na minha vida, eu montava um filme que eu iria voltar a filmar", ${ }^{4}$ diz o diretor. Dificuldades

4. Depoimento gravado em fita cassete no evento "Cineasta do Mês", no Centro Cultural Banco do Brasil (CCBB) do Rio de Janeiro, em 28 de maio de 1991. Acervo Projeto Cinema Alternativo. 
financeiras esgarçaram a montagem do filme por dois anos e, à medida que sentia necessidade de complementar o trabalho, Veríssimo convocava a equipe para a filmagem de mais alguns planos.

Exu-Piá se propõe menos como uma adaptação da obra de Mário de Andrade do que como um diálogo com ela e com o autor modernista. Isso fica claro na própria construção do filme: além da referência à obra literária, em momentos em que Grande Otelo aparece lendo o livro, há, em algumas sequências, a menção ao próprio Mário de Andrade, cuja imagem aparece pintada no quadro pendurado na parede de sua casa ou no busto que repousa numa praça. O busto de Mário de Andrade, animado pela voz de Paulo Gracindo, conversa com o herói. Disposto a pedir que o escritor mude o desfecho de sua história, Macunaíma viaja no tempo, chega à casa de Mário de Andrade e apela para ele: “Sabe, Seu Mário, é que o senhor podia ter-me feito diferente, nem tão doce nem tão amargo, nem tão frio nem tão quente. Eu não quero que Ci vá para o céu nem que roubem o que é meu”. Em outro momento, ele pede ao escritor: "O senhor fica me escrevendo e sempre sou em quem paga o pato. Vê se dá um jeitinho nesse último ato" (trecho do filme).

Exu-Piá dialoga não só com o livro de Mário, mas também com a antológica peça montada pelo diretor Antunes Filho e o Grupo Pau-Brasil, em 1978. Sua primeira intenção, aliás, era a realização de um documentário sobre a montagem que tanto o fascinara. O filme é entremeado por cenas da peça que pontuam momentos-chave da história, como o nascimento de Macunaíma, a morte da mãe, o encontro com a cascata, o envolvimento com $\mathrm{Ci}$, a morte da companheira e do filho, a volta para o Uraricoera. Herdeiro do reflexivo cinema moderno, o diretor utiliza, em muitos momentos, os bastidores da peça, como na sequência em que as atrizes que fazem as estátuas vivas da casa de Venceslau cobrem seus corpos com talco e são observadas de cima por um Macunaíma/Grande Otelo fascinado. 
A montagem de Macunaíma por Antunes Filho e o Grupo Pau-Brasil foi um

ano I número I

temáticas

livres marco para o teatro brasileiro. No processo de criação da peça, a metodologia utilizada foi a construção coletiva entre o diretor e os atores. No palco nu, os atores improvisaram os elementos cenográficos, utilizando-se de panos, trapos, sacos de lixo plásticos, jornais amassados. Segundo Edélcio Mostaço, se experiências como O rei da vela constituíram-se numa "antessala para a pós-modernidade", a montagem feita por Antunes Filho de Macunaíma pode ser considerada como uma "baliza na instauração do pós-moderno entre nós” (MOSTAÇO 2005: 571).

No filme de Paulo Veríssimo, à história de Macunaíma soma-se outra referência fundamental: o desfile da escola de samba Unidos da Tijuca, cujo enredo, intitulado $O$ que dá pra rir dá pra chorar, baseou-se em uma obra ficcional de Manuel Cavalcanti Proença, mais conhecido como autor do livro Roteiros de Macunaíma. No livro Manuscrito holandês - ou a peleja do caboclo Mitavaí contra o monstro Macobeba, Proença narra a luta do caboclo Mitavaí contra o monstro Macobeba, uma figura lendária proveniente de Pernambuco e que, no livro, representa os interesses do capital, como presidente de uma empresa chamada “VOFAVOFE - Vou fazer você feliz Colonizadora S/A" (SANTOS, 2008: 3).

No filme de Veríssimo, Mitavaí, como filho de Macunaíma (interpretado pelo ator Joel Barcelos), assume o cetro do pai, mantendo-o vivo. Anunciado como o guerreiro que virá para libertar o Brasil de suas mazelas, convoca o pai para juntar-se a ele numa luta, mas Macunaíma, por medo ou preguiça, disfarça para não participar. A luta é contra o monstro Macobeba, que "não gosta do que é nacional". Quando Mitavaí aparece pela primeira vez no filme, surge andando nos labirintos da favela onde mora, vestido de índio e portando a lança. Dentro da estrutura de colagem do filme, soma-se à sua imagem o verso do hino nacional - "e o teu futuro espelha essa grandeza" -, estampado no painel luminoso do Maracanã. Outros trechos do hino nacional que aparecem repetidamente no painel do estádio de futebol parecem querer reavivar no espectador o sentimento perdido pelo país. 
Veríssimo insere uma sequência, no final do filme, inspirada na história do flautista de Hamelin. Crianças surgem do alto das árvores e, encantadas com a melodia da flauta, seguem o guerreiro. Nesse contexto, Mitavaí aparece como uma figura que aponta para o futuro, livrando a sociedade dos ratos e apostando nas crianças como potencial de mudança.

No filme de Joaquim Pedro de Andrade, o fim trágico de Macunaíma representa, na opinião de Ismail Xavier, a declaração da morte simbólica do malandro, espécie de herói do folclore urbano brasileiro (XAVIER, 1993), recusando, assim, a identificação do personagem como figura anárquica contra a ordem estabelecida. Ao contrário, ao deixar-se levar pela preguiça e pelo jeitinho, Macunaíma integra o jogo do poder. Joaquim Pedro anseia por um novo herói, mais consciente, com sentido de coletividade e empenhado em um projeto comum. Diz ele:

O que falta ao personagem Macunaíma é uma visão mais geral, mais ambiciosa e mais consciente. Ele dá sempre seus golpes com sentido limitado, pessoal, individualista. É um estágio vencido - mas importante - do que seria o caminho para o herói moderno brasileiro. Macunaíma é o herói derrotado, que acaba comido pela Iara, abandonado e traído. (ANDRADE apud HOLLANDA, 1991: 115)

O diretor conclui, então, o que seria o herói moderno:

O herói moderno, para mim, é uma espécie de encarnação nacional, cujo destino se confunde com o próprio destino do seu povo. Uma das características fundamentais é a consciência coletiva. Ao contrário de Macunaíma, ele terá de encarnar um ser moral, no sentido de estar possuído por toda uma ética social. Ainda não apareceu o herói moderno porque ele terá de ser um vencedor, ao contrário do herói romântico, que era o herói vencido, triste. Em suma, o herói moderno terá de ser evidentemente uma superação de Macunaíma, embora conservando algumas características dele. (ANDRADE apud HOLLANDA, 1991: 115)

Seria o caboclo Mitavaí, filho de Macunaíma no filme de Veríssimo, o herói almejado por Joaquim Pedro? 


\section{Tropicalismo}

Ao lidar com todas essas referências, Paulo Veríssimo recria a história de temáticas Macunaíma, atualizando-a. Por isso, embora se trate de uma obra autônoma, é possível afirmar que o conhecimento prévio sobre o livro de Mário de Andrade - e sobre o que ele representa no contexto cultural brasileiro - pode tornar mais rico o entendimento do filme, incitando o espectador a processar os variados elementos referenciados pela história e, enfim, a montar (ou desmontar) o "bricabraque" proposto por Veríssimo, refletindo, a partir do presente, questões geradas no começo do século XX e que foram se transformando e diluindo, sem, no entanto, perder a pertinência.

Em Macunaíma, o contraste entre o texto repleto de referências à cultura popular, das lendas e nomes indígenas à religião negra, e a predominância da máquina na cidade flagram, em Mário de Andrade, a percepção da contradição que se estabelecia entre a inevitável modernização que se instalava no Brasil e a permanência de uma essência primitiva brasileira, com todos os riscos de se promover uma importação acrítica de modelos e estilos de vida que acabariam por tornar o brasileiro um ser sem personalidade, que nem teria seus pés fincados às raízes nem conseguiria se adaptar completamente ao novo tipo de civilização que lhe vinha sendo imposto.

Paulo Veríssimo retoma o veio cultural em torno da identidade brasileira presente no livro de Mário de Andrade e se aproxima da visão "tropicalista" do autor modernista:

Eu me sinto, sempre fui um tropicalista de primeira hora. Durante o processo de pesquisa do novo Macunaíma, eu li tudo de Mário. Um belo dia, achei uma carta de Mário de Andrade de 1925, 26, dizendose, confessando-se - eu não sou marxista, eu não sou de direita, eu não sou de esquerda, eu não sou social-democrata, eu sou tropicalista. ${ }^{5}$ Mário

5. Segundo Telê Ancona Lopez, essa ideia de "tropicalismo" está ligada à própria concepção sobre a civilização, que, para Mário, "equivale, então, a um problema de ecologia, isto é, à adequação 
dizia isso em 1926. Você imagina, o movimento tropicalista na arte, na cultura, vai explodir nos anos 60 e o Mário antevia tudo isso. Gostaria de falar desse tropicalismo enquanto assumir os trópicos, a sua terra, a sua maneira de ser, as suas peculiaridades, não se entregar, não se vender para o primeiro enfeite, para o primeiro adorno que a civilização colonial estrangeira superior lhe ofereça. O vietcongue é um tropicalista, ele ganhou uma guerra contra a maior nação do mundo utilizando arco e flecha; o outro com raio laser, ele com arco e flecha, ele foi garrincha o suficiente para ganhar uma guerra impossível. ${ }^{6}$

Ao se declarar como "tropicalista" de primeira hora, Veríssimo revela sua filiação ao movimento que marcou a vida cultural brasileira a partir de 1967. A década de 1960 foi marcada por uma rediscussão sobre a cultura nacional. No entanto, a apropriação pelo Estado repressor da bandeira do nacionalismo após o Golpe Militar tornava mais complicada a questão de se delinear uma identidade brasileira. A antropofagia oswaldiana foi retomada pelos tropicalistas em um momento em que os artistas brasileiros procuravam abrir-se para as transformações que se davam nas artes em nível mundial e, ao mesmo tempo, buscavam expressar as contradições culturais e políticas do país.

Identificado com as questões do período tropicalista, em Exu-Piá, Veríssimo procura mostrar a multiplicidade da identidade brasileira, fragmentada no Macunaíma negro, no Macunaíma caboclo e em Mitavaí. Em um momento, Grande Otelo senta na plateia do teatro para assistir à peça encenada pelo Grupo PauBrasil, e o narrador, em voz over, comenta como ele estava impressionado ao ver sua própria história encenada no palco. Há um redescobrimento do personagem por ele mesmo, uma reflexão de como as coisas poderiam ser diferentes.

do homem ao seu meio, inclusive o clima, que no caso brasileiro é propício à preguiça. A idéia lhe vem possivelmente da observação da perfeita vivência tropical na Amazônia [...]. A Amazônia sentida nas lendas de Macunaíma e conhecida de perto em sua viagem de 1927 já se anuncia, no romance Macunaíma, como o centro da unidade do ser, recuperando-se das atribulações do progresso. [...] A adesão ao tropicalismo brasileiro, que apresenta em 1926, é a mesma que será sistematizada pela Antropofagia em 1928" (LOPEZ, 1972: 111).

6. Depoimento gravado em fita cassete no evento "Cineasta do Mês", no Centro Cultural Banco do Brasil (CCBB) do Rio de Janeiro, em 28 de maio de 1991. Acervo Projeto Cinema Alternativo. 
ano I número |

temáticas

livres

O Macunaíma de Paulo Veríssimo é um personagem quase ingênuo. Ele está encarnado, por exemplo, em Garrincha, o jogador brilhante e alegre que, após o auge da carreira, ficou esquecido até sua morte. Ao contrário de Joaquim Pedro de Andrade, que, em sua versão da história, muda o final de Mário de Andrade e decreta a morte do herói ao ser engolido pela Uiara, Paulo Veríssimo lamenta seu desaparecimento sem que tenha recebido o devido valor. Esse lamento correspondendo na imagem às cenas do funeral de Garrincha - é exteriorizado no filme na voz de Maanape, um dos irmãos de Macunaíma: "Eu não posso ver você assim, Coração dos outros. Isso não é fim para herói que se preza, Piá". Enquanto canta Elis Regina ("o Brazil está matando o Brasil”), Veríssimo alterna planos de Garrincha coberto com a bandeira brasileira, planos do jogador no campo, do velório e do caixão em cortejo pelas ruas da cidade, sob o olhar entristecido dos torcedores.

Filmando já na década de 1980, Veríssimo retoma questões delineadas na década de 1920 e retomadas em fins de 1960, com o Tropicalismo. Tão inspiradores quanto a obra original de Mário de Andrade são a peça de Antunes Filho, principalmente, e o filme de Joaquim Pedro. Antropofagia é o método incorporado por Veríssimo: filme fragmentário, colagem de imagens e sons, somatório de referências da cultura popular urbana e da cultura de massa, a partir de um clássico da literatura brasileira.

O diretor ressalta a eterna busca do brasileiro pela descoberta de sua identidade. Embora não seja um filme linear, nos moldes a que o espectador comum está acostumado, podemos considerar que se trata, sim, de um filme popular: o humor, o carnaval, o futebol, a música forte e vibrante, a sensualidade aproximam o filme do universo do espectador brasileiro. No entanto, um espectador mais treinado poderá perceber uma gama de referências à própria história da cultura brasileira, desde o Modernismo até o momento em que o filme foi feito.

Nada mais tropicalista... 


\section{Referências bibliográficas}

ANDRADE, Mario de. Macunaíma, o herói sem nenhum caráter. São Paulo: Livraria Martins.

ANDRADE, Oswald de. A utopia antropofágica. São Paulo: Globo, 1990.

ÁVILA, Afonso. (Org.). O modernismo. $2^{\text {a }}$ ed. São Paulo: Perspectiva, 2002. (Coleção Stylus)

BASUALDO, Carlos. Tropicália: a revolution in Brazilian culture. São Paulo: Cosac Naify, 2005.

FAVARETTO, Celso. Tropicália, alegoria, alegria. São Paulo: Ateliê, 1996.

HOLLANDA, Heloisa Buarque de (Org.). Pós-modernismo e política. Rio de Janeiro: Rocco, 1991.

LOPES, Telê Porto Ancona. Mario de Andrade: ramais e caminhos. São Paulo: Livraria Duas Cidades, 1972.

MORAES, Eduardo Jardim de. A brasilidade modernista: sua dimensão filosófica. Rio de Janeiro: Edições Graal, 1978.

MOSTAÇO, Edélcio. "O teatro pós-moderno”. In: GUINSBURG, J.; BARBOSA, Ana Mae. O pós-modernismo. São Paulo: Perspectiva, 2005. (Coleção Stylus)

NAGIB. Lúcia. A utopia no cinema brasileiro. São Paulo: Cosac Naify, 2006.

SANTOS, Luiza Aparecida Oliva; MOTTA, Sérgio Vicente. "Cavalcanti Proença: quadros de mitopoética". XI Congresso Internacional da ABRALIC. 13 a 17 de julho de 2008. USP - SP. Disponível em: ww w.abralic.org/anais/cong2008/AnaisOnline. Acesso em: 01 de outubro de 2009.

XAVIER, Ismail. Alegorias do subdesenvolvimento: Cinema Novo, Tropicalismo, Cinema Marginal. São Paulo: Brasiliense, 1993. 